\title{
Does World Natural Heritage status trigger sustainable regional development efforts?
}

\author{
Katharina Conradin \& Urs Wiesmann
}

Keywords: World Natural Heritage sites, international label, impacts of conservation, sustainable regional development, conservation debate, soft success factors, global survey

\section{Abstract}

Today, there are over 200 World Natural Heritage (WNH) sites. Although the original aim of the World Heritage (WH) Convention was to spark off concerted international efforts to preserve sites of outstanding and universal value, today a multitude of expectations rests on WNH sites in terms of conservation, tourism, management and regional development. This paper identifies the effects of WNH status on sustainable regional development and the driving factors behind these effects. The results are based on a global survey of WNH sites and qualitative interviews with key WNH personnel. The paper shows that WNH status can be an important trigger for sustainable regional development, but its effectiveness depends on a number of intricately interwoven 'soft' success factors. Clearer policies and management guidelines, as envisaged by UNESCO, are crucial to achieving a balance between conservation and development.

\section{Introduction}

With an average of 23 new sites per year in the last decade, WH status is as coveted as ever. Since the Convention Concerning the Protection of the World Cultural and Natural Heritage was established in 1972 (UNESCO 1972), the WH label has been awarded to 193 protected areas, 759 cultural sites, and 29 mixed properties (UNESCO 2013). Past research related to WH, and in particular World Natural Heritage (WNH), status consists mainly of individual or nationwide case studies (Tisdell \& Wilson 2001; Buckley 2004; Li et al. 2008), or of commissioned reports that typically focus on economic effects (Hambrey 2007; Prud'homme et al. 2008; Rebanks 2009). Many of the more geographically comprehensive studies take up one particular aspect, such as tourism issues or social implications (Jha 2005), promotional advantages (Marcotte \& Bourdeau 2012) or representativeness (Hazen \& Anthamatten 2007). These studies do not allow us to fully understand the interrelations between $\mathrm{WNH}$ sites as protected areas and processes of regional development.

At the same time, approaches to protected area management have changed considerably during the late $20^{\text {th }}$ century (Slocombe \& Dearden 2002; Mose \& Weixlbaumer 2012). Today, protected areas are increasingly seen as triggers for sustainable regional development. Ongoing discussions regarding the post-2015 development agenda highlight the importance of conservation for sustainable development, which was defined by Brundtland (1987: 41) as development that meets the needs of the present without compromising the ability of future generations to meet their own needs. Griggs et al. (2013: 306) suggest a crucial adaptation to this definition, Sustainable development is development that meets the needs of the present while safeguarding Earth's life-support system, on which the welfare of current and future generations depends. In this view, environmental conservation becomes an essential part of fulfilling social and economic needs with protected areas playing a substantial role in achieving this goal. Sustainable regional development then means that the principles of sustainable development are implemented at a regional (i.e. subnational) level (Lonergan 1993; Clement 2005: 263). As Böcher (2009: 127) notes, the regional level is considered a particularly meaningful frame of reference for sustainable development because the cause and effect of human interventions are directly visible. The WNH region understood as an area larger than the actual site itself, i. e. the WNH's sphere of influence - thus seemed an appropriate frame of reference to catch also those effects beyond the boundaries of individual sites.

It is therefore useful to raise the question of what role WNH status plays in this regard. Building on a global survey of more than $60 \%$ of all WNH sites listed in 2011 (128 out of 211) and 34 in-depth interviews, this paper identifies the effects that can be attributed to WNH status. It furthermore examines why some WNH sites seem to be more effective at promoting sustainable regional development than others. This first comparative and global survey shows that the contribution of WNH sites to sustainable regional development should not be underestimated. Yet it also highlights that a site's contribution depends heavily on a network of interrelated and primarily soft factors.

\section{Methodology}

A global survey of all listed WNH sites was conducted in spring 2012; the response rate was more than $60 \%$ (128 sites, see Figure 1). To complement the survey, 34 in-depth interviews were conducted. The core aim was to find out how WNH status contributed to sustainable regional development and which factors influenced this contribution.

A grounded theory approach was chosen for the study. Developed by Corbin \& Strauss in the late 1960s (Corbin \& Strauss 2008) and recently sum- 


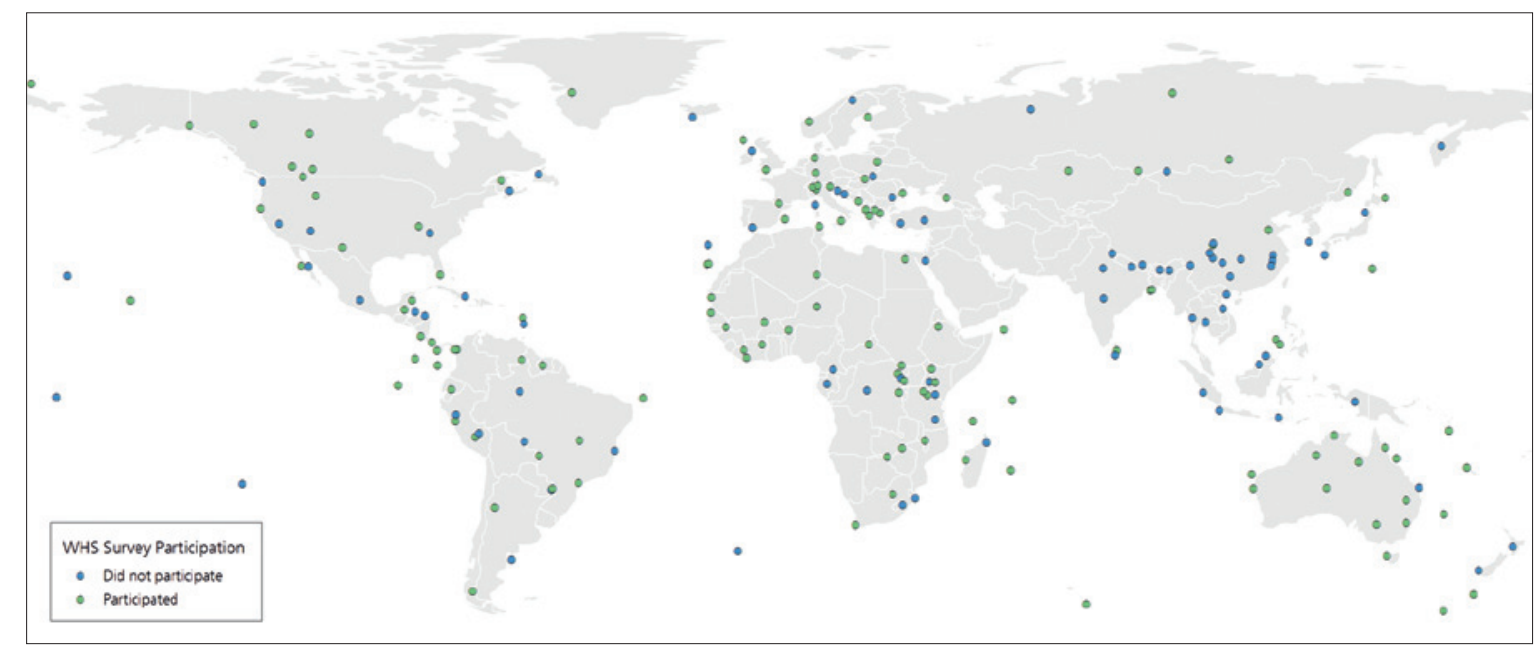

Figure 1 - Overview of the participating WNH sites. Map design: Matthias Engesser

marized at a practical level by Urquhart (2013), this social-science approach is based on the idea that a continuous evaluation of research findings and their integration into subsequent research steps allows theories to emerge. For this study three initial regional case studies were conducted in Kenya, Tanzania, and Switzerland (Conradin et al. 2014). The knowledge thus gained formed the basis of a Driving Force - Pressure - State - Impact - Response framework (EEA 2006) that was used to identify relevant questions in the context of conservation / use. These questions were then subdivided into ecological, social, economic and institutional indicators. In contrast to the many frameworks of indicators that exist for sustainable development, this practical approach identified the questions that were both universal and practical enough to address the different WNH sites' realities.

These questions were incorporated in a questionnaire provided to respondents in an online format. Backed up with a database specifically compiled for this survey, this setup allowed us to individually adapt each questionnaire with existing site-specific figures and statistics. The questionnaire was sent to the managers of all 211 natural and mixed sites included on the WH list in 2011 (in this paper, hereafter the mixed sites will also be subsumed under WNH sites).

To distinguish between effects independent of / influenced by WNH status, the survey always asked for the current state of a respective indicator, likely development trends and the impact of WNH status on the respective indicator. As responses required a high level of knowledge regarding the WNH site in question, we addressed the site managers or the responsible public authorities directly. Overall, $45 \%$ of responses came from the top management, $27 \%$ from senior staff, $12 \%$ from public authorities and 16\% from advisors, researchers or assistant staff. While about $10 \%$ of the respondents had a background in tourism or regional development, the remaining 90\% were split about equally between respondents with a conservation and those with a management background. In total, 128
WNH sites completed the survey (five of them partially). Answers were given on a three to five point scale, ranging from very negative or no impact to very positive. Each question allowed for individual comments, a function that was used extensively.

To gain a broader understanding of the responses and to triangulate the data, 34 qualitative interviews were carried out with participants. Interview partners were selected from the survey participants based on cases that offered explicative information for trends detected in the quantitative analysis. Semi-structured interviews were conducted according to Flick (2009: 194), either in situ or via Skype.

Quantitative data were analysed with the Statistical Programme for the Social Sciences (SPSS), with a particular focus on identifying the effects induced after WNH status had been granted. The interviews and qualitative answers were analysed and coded with Atlas.TI.

\section{Protected areas and regional development}

Approaches to and values with regard to protected area management have changed considerably over the past century, influencing the current understanding and use of $\mathrm{WNH}$ status. The beginnings of nature conservation in its modern form date back to the late 1800s, when the first national parks were established (Nash 1980). Contrasting understandings of conservation emerged early on: while preservationists advocated for $[. .$.$] wild areas that were set aside from all de-$ velopment or commercial use whatsoever, (Henderson 1992: 396), conservationists followed a utilitarian approach that aimed at establishing a way of managing natural resources (especially forests) that would conserve the resource while delivering the greatest benefit to mankind (Fox 1985: 115-117).

Towards the end of the $19^{\text {th }}$ century, preservationist approaches became the dominant form of conservation. According to Mose \& Weixlbaumer (2012: 117), many of the protected areas established at that time followed an approach that strictly separated conserva- 


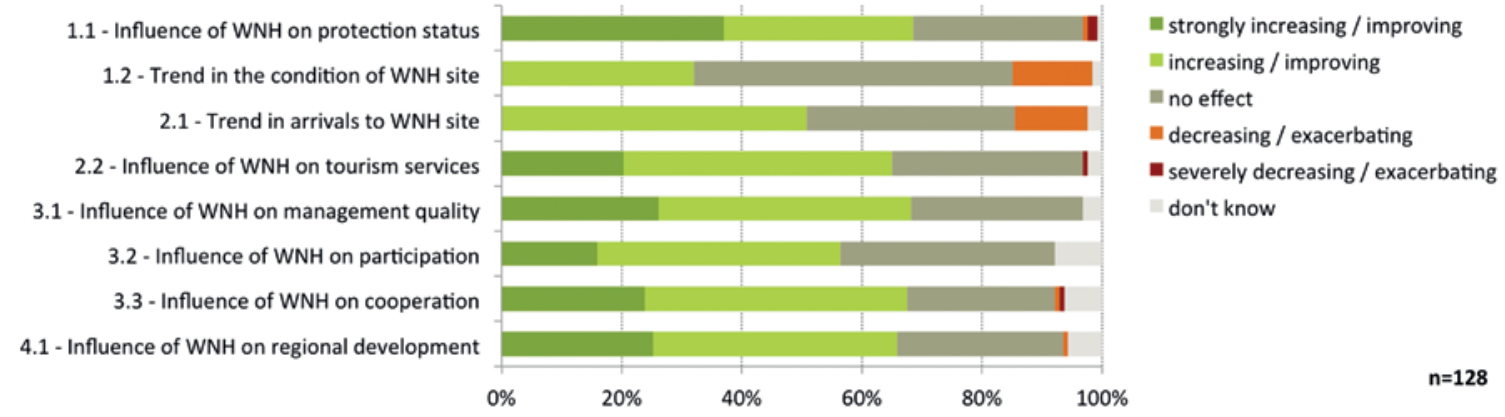

Figure 2 - Effects of WNH status (designed by the authors).

tion and use, though different policies always co-existed. They argue further (ibid. 118) that the $20^{\text {th }}$ century brought with it a slow but constant move away from the original static-preservation approach towards a dynamic-innovation approach. The changing approaches to protected area management were certainly influenced by changes in the understanding of the human-environment relationship, where human beings are viewed as part of the natural world rather than separate from it (see MeyerAbich 1990). This understanding essentially fostered a view of protected areas increasingly seen as potential model regions where conservation and development could combined (see Hammer 2003; Mose 2007).

This new paradigm is reflected in various policies that have influenced the understanding of WNH sites and hence also their motivations and management approaches: UNESCO's 1971 Man and the Biosphere programme was established with the aim of demonstrating innovative approaches to living and working in harmony with nature; the Seville Strategy in 1995 further solidified the idea that the conservation of nature should not be seen as isolated from the needs of humankind. The word sustainable first appeared in 1994 in the Operational Guidelines for the implementation of the World Heritage Convention (UNESCO 1994: 14) with regard to cultural landscapes. Yet, the role of WNH sites as contributors to sustainable development was only explicitly mentioned in the Budapest Declaration of 2002, which seek $[s]$ to ensure an appropriate and equitable balance between conservation, sustainability and development, (WHC 2002: 6). This declaration can be considered the beginning of an ongoing process of integrating the concept of sustainable development into the WH convention (see, for instance, WHC 2009; WHC 2010b; WHC 2012). However, the practical potential of $\mathrm{WNH}$ sites to act as triggers for sustainable regional development was recognized much earlier, as the focus of WNH management widened from ensuring conservation to contributing to development in a broader sense (see Conradin 2014).

\section{Effects of World Heritage status}

These changing values regarding protected areas influence WNH sites and the way they are understood. The WH Convention was created at a time when rapid growth threatened some of the world's greatest natural and cultural heritage sites, and the understanding that WNH status would protect these sites from negative human influence therefore lies at the core of the WH Convention (UNESCO 1972). However, the paradigm changes described above have led to WNH status increasingly being seen as a promotional label. Clearly, WNH status has effects other than conservation.

The following section provides a brief overview of the effects attributed to WNH status and examines the factors that influence the delivery of these effects. For this paper, an example was chosen for each of the three dimensions of sustainability (see Figure 2): conservation (environmental), tourism (economic), inclusive management approach (social) - the overall effect being evaluated at the end of this section.

\section{Environmental impacts - conservation}

Most respondents indicated that WNH status had a decisive influence on the protection status of a site, despite the fact that the WH Convention, as an international treaty, respects the sovereignty of signatory states (UNESCO 1972: 6) and therefore has limited power to influence national protection policies. Nevertheless, $70 \%$ of respondents (Figure 2,1.1) stated that the sites' protection status had increased after inclusion in the list. The international recognition of the label, potential reputational damage in case of its loss and potential international support in crises are policy instruments that can lead to adaptations in national legislation. In particular, respondents stressed that WNH status provides an additional layer of conservation: "WH status helped to create visibility and enhance awareness of the growing threat to the [...] ecosystem, thereby attracting more attention and an increased level of external support, especially funding," (ID 262). Over 85\% of respondents additionally noted that WNH status contributes to conserving the outstanding universal value of the site in general, "Markedly, without WNH status and the resulting funding partnership between the State and [the] government, the inherent value would have been compromised," (ID 231). Other researchers confirm the effect of WNH status on conservation (Wiesmann \& Liechti 2004; Tisdell 2010: 31). In total, $85 \%$ of respondents felt that the general state of their WNH site was either improving $(32 \%)$ or stable $(53 \%$; Figure $2,1.2)$. This is significant, as over $40 \%$ of all participants reported an increase in threats to the WNH site, particularly from tourism. 
Economic effects - tourism

An increase in visitor numbers over the past five years was noted at more than half of all participating sites. Respondents also frequently mentioned a rise in international visitors (Figure 2, 2.1). This is in line with the increase in visitors to protected areas regarded as icons of pristine nature (Reinius \& Fredman 2007: 839). WNH status is increasingly considered an indication of sites that are particularly worth visiting (Tisdell 2010: 32). Yet, while the impact of WNH status on visitor numbers is very difficult to distinguish from the impact of the general iconic value of the site, case study findings indicate that WNH status contributes to increasing general awareness of the site and thus indirectly to its tourist value (see also Conradin et al. 2014: 46). Many scholars have confirmed the effect of WNH status on tourism (e. g., Buckley 2004; Li et al. 2008; Engels et al. 2011; Marcotte \& Bourdeau 2012), making it clear that the promotional value of $\mathrm{WNH}$ status should not be underestimated. One interviewee even went so far as to say: "In my opinion, the motivation for a WNH status application [...] can only be better marketing," (ID 164.2).

Despite its economic benefits, the rise in tourism is increasingly considered a threat to the natural value of WNH sites. Noting that $2-8 \%$ of all inscribed WNH sites report serious environmental problems related to tourism every year, Engels et al. (2011) regret the lack of tourism-specific management principles. UNESCO has, however, recognized this need and has issued numerous guidelines (e. g., Pedersen 2002; UNESCO et al. 2012) and initiated a sustainable tourism programme (see WHC 2010a; UNESCO 2014). However, implementing principles that lessen the negative impacts of tourism on WNH sites and support the development of sustainable forms of tourism remains a challenge. In our study two-thirds of respondents indicated that WNH status has had a positive influence on the quality of the tourism services offered, such as educational offers, creation of or improved compliance with sustainability standards, better social standards, or improved tourism policies (Figure 2, 2.2). Nevertheless, as sustainability is a normative concept, these impacts are likely to vary in quality. In addition, two-thirds of all participating WNH sites point out that tourism generates funds for conservation. Likewise, Tisdell (2010: 28) notes that if economic benefits can be generated from protected areas, conservation is more likely to be supported by policy. These positive aspects of tourism at WNH sites must be weighed against the negative impacts mentioned above.

Social impacts - management and participation

WNH status has a significant impact on the management structure and approach of a site (Figure 2, 3.1), in part because UNESCO requests a comprehensive management plan (UNESCO 2011: 27). This, together with the fact that inclusion in the WH list is often accompanied by additional funding for the site's management, is certainly why nearly $70 \%$ of all participating sites said WNH status had positively influenced the management quality of the site; none of the sites noted a negative effect. Participants also indicated that WNH status led to an increase in participation by civil society $(56 \%)$ and to cooperation between different stakeholders (68\%) (Figure 2, 3.2 and 3.3), both of which are important when it comes to resolving conflicting interests. These findings are confirmed by numerous case studies (see e.g. Galla 2012). Survey results also show that WNH status has a mitigating influence on conflicts in about a third of the cases; very few sites noted an aggravation of conflicts after WNH status had been granted. For example, the formation of communal Water Resources Management Associations following the establishment of the Mt Kenya WH site has very effectively addressed critical water issues in this area (see also Conradin et al. 2014).

Assuming a holistic understanding of sustainable regional development as described above, the contribution of WNH sites to this goal must not be underestimated. Successful WNH sites have the potential to influence all spheres of sustainable development: environmental (e.g., through conservation and sustainable land-use practices), economic (e.g., through tourism or productive activities) and social (inclusive multi-stakeholder management, participation, poverty-alleviating development). This potential is recognized by UNESCO and supported through various programmes (e.g. the successful COMPACT programme, see Brown et al. 2010). About two-thirds of all participating sites, themselves assuming a comprehensive understanding, valued the contribution of their WNH site to sustainable regional development as significant or very significant (Figure 2, 4.1). WNH sites, especially in the global South, have crucial ecosystem functions as water towers, biodiversity hotspots or important resource areas (see Wiesmann \& Liechti 2004), therefore the conservation of these resources must clearly be at the core of any sustainable development strategy. The following quote by a southern interviewee, after stressing the importance of WNH status to conservation, exemplifies this, "The fact that we have this international designation is generating an intangible value in itself. For instance, the generation of oxygen by the large forest reserves, the sequestration of carbon dioxide in [the park's] large forests, the production of fish in the mangrove zones, the mitigation of climate change and of tropical storms these are a series of benefits that our WNH site is creating to maintain an ecosystem within and around the reserve. So the site is at the basis of sustainable development," (ID 434).

\section{Success factors}

Whether and to what degree the impacts mentioned above are actually achieved, and to what extent a protected area can contribute to regional development processes, depends largely on framework con- 


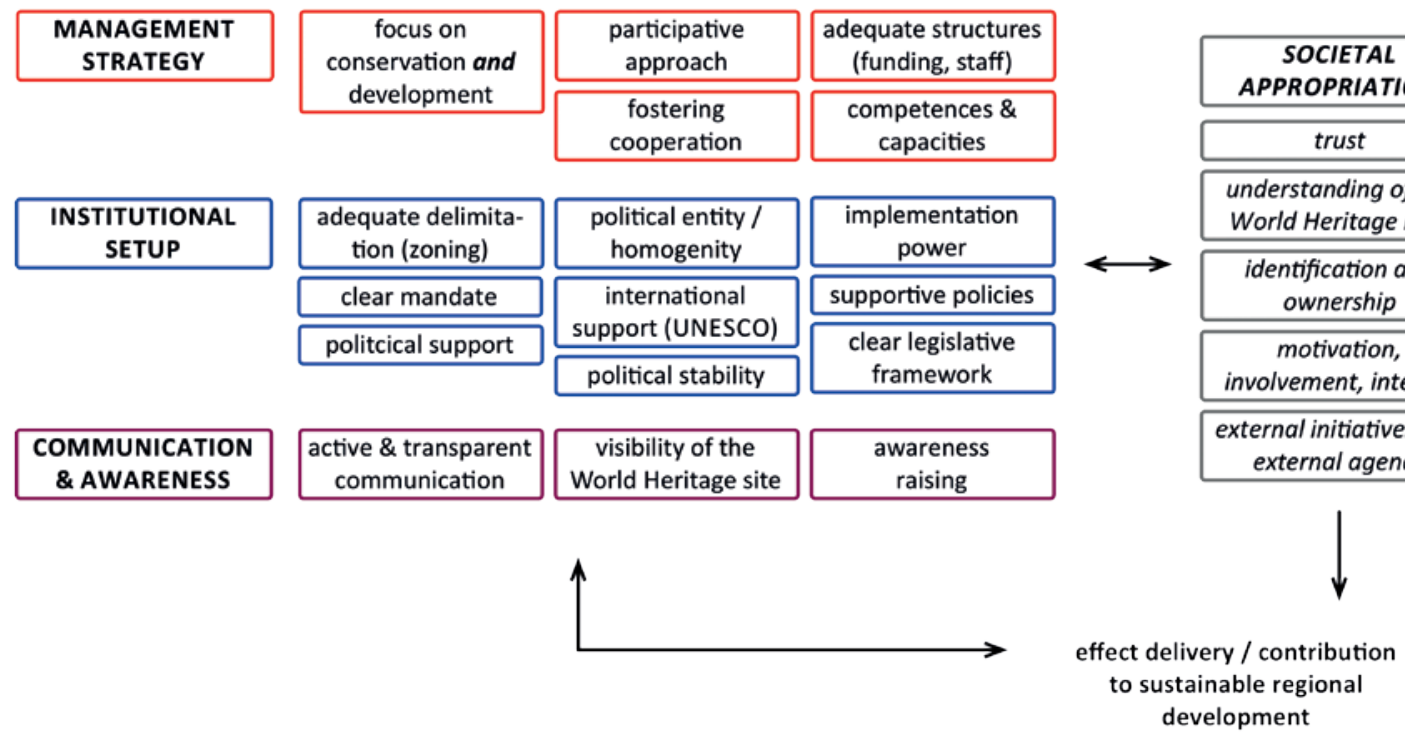

Figure 3 - Overview of soft success factors influencing the delivery of benefits (own figure based on survey and interview results)

ditions. In 34 qualitative interviews, we focused on these success factors, which, if lacking, can impede the achievement of set targets. The identified factors are presented in Figure 3. Although it is obvious that capable management, adequate personnel and appropriate funding are necessary, the majority of factors that influence the effectiveness of a WNH site are so-called 'soft' success factors that are all strongly interlinked and interdependent. In this paper, we have grouped these factors into three thematic areas: management strategy, communication and awareness, and institutional setup. The decisions taken and approaches chosen in these three areas significantly influence what we shall call societal appropriation. We consider societal appropriation - the identification of stakeholders with a site and subsequent activities to fill it with life - fundamental to the delivery of benefits of WNH sites.

The soft success factors identified in the survey and the interviews are summarized in Figure 3 and discussed below.

\section{Management strategy}

A WNH site that is to deliver both conservation and development effects clearly needs a strategy encompassing both aspects. A study by Conradin (2014) showed that the motivation of $\mathrm{WNH}$ sites (i.e. whether a site is more oriented towards conservation or development) significantly influences the impacts achieved by WNH status. Sites that follow a more development-oriented approach achieve more results in terms of sustainable regional development, whereas conservation-oriented sites have a lesser overall impact (ibid.). Rebanks 2009 reports similar findings from a comparative study. Respondents have identified participative approaches that foster cooperation as crucial in this respect. Böcher (2009: 129) argues that participation and cooperation are particularly important because sustainable regional development is a cross-sectional task that requires the involvement of a variety of stakeholders with different interests. Our survey results clearly indicate that the impact of WNH status on sustainable regional development is significantly higher at sites where participation by civil society has increased (nearly $90 \%$ of participants see an impact) than at sites with no change in participation (little more than $40 \%$ see an impact).

The importance of participative approaches in WNH management has been confirmed in numerous studies, yet the manner in which participatory management is actually implemented can make a big difference (see Wallner \& Wiesmann 2009; Conradin et al. 2014). In fact, this is another example in which the requirements of the WH convention - i.e., the participation of different stakeholders - very directly influence the management approach of the site. The change from top-down decision making to multistakeholder decision-making processes is also a crucial postulate for the post-2015 sustainable development goals (IRF 2013). As one participant noted, "Many different stakeholders are involved in terms of conflict resolution and consensus building, but we do not give single parties the right or the possibility to dominate a decision-making process. The management centre ensures that equal importance is given to opinions of environmental, societal and economic circles, according to the principle of the local agenda 21," (ID 164.3).

\section{Communication \& awareness}

The continued participation and involvement of stakeholders depends strongly on consistent communication about issues surrounding the WNH site, its core goals and aims, potential consequences and opportunities the status provides. "Protected areas need a certain amount of communication activities. That is why [communicated] offers are very important, so that people identify with the area and are also willing to protect it: 'You only protect what you know'," (ID 164.4). Communicative activities raise the visibility of the WNH site and awareness of its unique values. This is crucial for a society's identifi- 
cation with and appropriation of the WNH site (see below). Roberts \& Jones (2013: 37) reached similar conclusions in their research on community engagement in conservation.

\section{Institutional aspects \& policy}

Protected areas today are situated at a nexus of different values. Societal as well as political trends make the acceptance of protected areas increasingly dependent on their delivery of economic benefits in addition to their core aim of conserving natural resources (see Tisdell 2010: 28). Because of their international reputation, WNH sites are particularly exposed to this trend. Survey participants stressed the importance of a clear management mandate and the need for clearly communicated objectives. Unclear or vaguely communicated goals may lead to expectations that are not fulfilled and, eventually, to a lack of societal support: "We do have strategic goals, but [...] ours is not to create added value. Almost daily I ask myself how to deal with this because I am confronted with this expectation every day," (ID 354). Clearly the responsibility for the delivery of effects lies not only with the management but is strongly influenced by the relevant policies. A clear legislative framework, as well as institutions empowered to implement it, are crucial to achieving benefits (see the Mt Kenya example in Conradin et al. 2014).

With regard to a supporting legislative framework, the importance of adequate zoning is increasingly recognized (see for instance Geneletti \& van Duren 2008), in particular when it comes to integrating WNH sites into regional planning. Many of the survey participants stressed that WNH sites that involve properties of different political entities are more difficult to manage than sites that match administrative entities. Complicated administrative arrangements and institutional collaborations may not be the only reasons for a complicated development process; the lack of a common identity also makes it difficult to manage WNH sites that cross multiple political boundaries. Identity always needs a constitutive other, i.e. what one is not (Meinhof \& Galasiński 2005: 8), and administrative borders often separate such spheres of identification. Finally, respondents consider international support by UNESCO crucial. Particularly in times of crisis, the international label is a powerful argument for safeguarding the site: "During that time [of war], it was important to have the WNH status. It enabled us to take the role of a background agent, which encouraged the governments to make efforts with us as the managers of the park to assure its safeguarding," (ID 417).

\section{Societal appropriation}

Clearly, management strategy, communication activities and institutional aspects critically influence societal appropriation of the WNH site. Societal appropriation is here understood as a common vision of what the WNH site is, its aims and the feeling of joint ownership. Societally appropriated projects trigger a certain feeling of responsibility among stakeholders. As an interviewee put it, "Awareness among people that they live in one of the most valuable and most beautiful landscapes worldwide must be increased. Among regional economic stakeholders, the awareness should be improved that the WNH obliges them to act carefully and sustainably. This would lead to new opportunities," (ID 164.3). Similarly, Weichhart (1992: 31f) suggested that the identification of a population with a certain spatial entity (e.g. a region) strengthens the ties between the population and the respective area, creating a feeling of loyalty and responsibility. Such identification is thought to lead to external initiatives that complement the work of the management. Many interview partners stressed the importance of 'external agency' for the effectiveness of WNH sites in regional development, as it aids in reaching set targets. Liechti et al. 2010 describe how the societal appropriation of the Jungfrau-Aletsch WNH site in the Swiss Alps was initially complicated by contrasting concepts of landscape and nature, but how an extensive participatory process eventually contributed to a common frame of reference. The normative ideal of sustainability can in reality change from a term of consensus to a term of conflict, as Böcher (2009: 130) rightly notes. Overall, the absence of such a common understanding - which is itself influenced by the chosen management approach, communication strategy and institutional setting - decisively influences the successful implementation of a WNH and the delivery of effects.

\section{Conclusion}

Both the global survey and the interviews show that WNH status is in fact effective in promoting benefits beyond conservation that contribute to sustainable regional development. Yet none of the induced effects occur of their own accord; they are the result of careful planning and a complex interplay of hard and, in particular, soft success factors. Sites that have been able to use their WNH status to carefully devise an appropriate management strategy, focus on an integrative approach and benefit from an enabling institutional environment deliver more positive effects than those where the WNH status is simply used as an additional label.

As a normative concept, sustainability must constantly be redefined for specific local settings. The increasing commercial utilization of the WNH status makes it clear that the economic aspects of sustainability are often weighted more than the social or ecological aspects, putting the inherent value of WNH status at risk. Although WNH sites make an important contribution to sustainable regional development, finding the right balance between conservation and development remains a challenge. The fact that the aims of the WH Convention focus on conservation does not help the situation. Rather, it seems that the gap is growing between the Convention's original aim (that 
of conserving sites of outstanding universal value) and reality (that an increasing number of $\mathrm{WNH}$ sites are brand names for sites particularly worth visiting).

UNESCO itself has recognized these tensions and is working towards integrating sustainable development into the WH convention - a crucial step. To harness the potential of WNH sites for fostering sustainable regional development, internationally accepted policies are needed as well as clear and binding guidelines for the management of WNH sites. Such policies must be founded on the understanding that the natural environment and its protection are the basis of sustainable regional development. They must also consider WNH sites as development nuclei for their entire WH region. Such a zoned approach allows site managers to take the necessary steps to conserve the outstanding universal value of a site, whilst integrating it into the social, environmental and economic ecology of the region.

\section{Acknowledgements}

The authors wish to acknowledge support from the Swiss National Centre of Competence in Research (NCCR) North-South, co-funded by the Swiss National Science Foundation (SNSF), the Swiss Agency for Development and Cooperation (SDC) and the participating institutions.

\section{References}

Böcher, M. 2009. Faktoren für den Erfolg einer nachhaltigen und integrierten ländlichen Regionalentwicklung. In: Friedel, R. \& E.A. Spindler (eds.), Nachhaltige Entwicklung ländlicher Räume. Wiesbaden: 127-138.

Brown, J., A.M. Currea \& T. Hay-Edie 2010. COMPACT. Engaging Local Communities in Stewardship of Globally Significant Protected Areas. New York: The Global Environmental Facility Small Grants Programme.

Brundtland, G.H. 1987. Towards sustainable development. In: World Commission on Encironment and Development (ed.), Our Common Future. Oxford: 43-65.

Buckley, R. 2004. The effects of world heritage listing on tourism to Australian national parks. Journal of Sustainable Tourism 12 (1): 70-84.

Clement, K. 2005. Environment and sustainable regional development. European Environment 15 (5): 263-265.

Conradin, K. 2014. World Heritage, conservation and regional development. In: Gravari-Barbas, M. \& S. Jacquot (eds.), Patrimoine mondial et développement, au défi du tourisme durable. Québec: 47-76.

Conradin, K., M. Chyumba, K. Boniface, S.N. Mwaura \& K. Liechti 2014. World Natural Heritage sites and regional development - the cases of Mt Kenya and Mt Kilimanjaro. eco.mont 6 (1): 25-28.

Corbin, J. \& A. Strauss 2008. Basics of qualitative research. $3^{\text {rd }}$ edition. Los Angeles.
EEA - European Environment Agency 2006. The DPSIR framework used by the EEA. Available at: http://root-devel.ew.eea.europa.eu/ia2dec/ knowledge_base/Frameworks/doc101182 (accessed: 10/05/11)

Engels, B., K. Manz \& B. Job-Hoben 2011. Weltnaturerbe und Tourismus - Herausforderungen und Chancen. Natur und Landschaft 86 (12): 527-533.

Flick, U. 2009. An introduction to qualitative research. $4^{\text {th }}$ edition. London.

Fox, S. 1985. The American conservation movement. John Muir and his legacy. Madison, Wisconsin.

Galla, A. 2012. World Heritage: benefits beyond borders. Cambridge, Paris.

Geneletti, D. \& I. van Duren 2008. Protected area zoning for conservation and use: A combination of spatial multicriteria and multiobjective evaluation. Landscape and Urban Planning 85 (2): 97-110.

Griggs, D., M. Stafford-Smith, O. Gaffney, J. Rockström, M.C. Öhman, P. Shyamsundar, W. Steffen, G. Glaser, N. Kanie \& I. Noble 2013. Sustainable development goals for people and planet. Nature 495 (21 March 2013): 305-307.

Hambrey, J. 2007. Social, economic and environmental benefits of World Heritage sites, Biosphere Reserves, and Geoparks. Perth (GB): Scottish Natural Heritage Commissioned Report NO. 248 (ROAME No. F06NC05).

Hammer, T. 2003. Grossschutrgebiete: Instrumente nachhaltiger Entwicklung. Munich.

Hazen, H. \& P. Anthamatten 2007. Unnatural selection: an analysis of the ecological representativeness of natural World Heritage sites. The Professional Geographer 59 (2): 256-268.

Henderson, N. 1992. Wilderness and the nature conservation ideal: Britain, Canada, and the United States contrasted. Ambio 21 (6): 394-399.

IRF 2013. Post-2015: framing a new approach to sustainable development. Policy Paper. S.L.: Independent Research Forum.

Jha, S. 2005. Can Natural World Heritage Sites Promote Development and Social Harmony? Biodiversity and Conservation 14 (4): 981-991.

Li, M., B. Wu \& L. Cai 2008. Tourism development of World Heritage sites in China: a geographic perspective. Tourism Management 29 (2): 308-319.

Liechti, K., A. Wallner \& U. Wiesmann 2010. Linking a World Heritage site to sustainable regional development - contested natures in a local negotiation process. Society \& Natural Resources 23 (8): 726-741.

Lonergan, S. 1993. Sustainable regional development. Canadian Journal of Regional Science / Revue Canadienne des sciences régionales 16 (3): 335-339.

Marcotte, P. \& L. Bourdeau 2012. Is the World Heritage label used as a promotional argument for sustainable tourism? Journal of Cultural Heritage Management and Sustainable Development 2(1): 80-91.

Meinhof, U.H. \& D. Galasiński 2005. The language of belonging. New York. 
Meyer-Abich, K.M. 1990. Revolution for Nature. From the environment to the connatural world. Denton.

Mose, I. 2007. Protected areas and regional development in Europe: Towards a new model for the 21 sentury. Ashgate Studies in Environmental Policy and Practice. Surrey, Burlington.

Mose, I. \& N. Weixlbaumer 2012. A shift of paradigm? Protected areas policies in Europe in transition by the example of the Hohe Tauern national park. In: Weixlbaumer, N. (ed.) Anthologie zur Sozialgeographie. Vienna: 106-124.

Nash, R. 1980. The confusing birth of national parks. Michigan Quarterly Review 19 (2, Spring): 216-226.

Pedersen, A. 2002. Managing tourism at World Heritage sites: a practical manual for World Heritage site managers. World Heritage Manuals. Paris.

Prud'homme, R., M. Gravari-Barbas, S. Jacquot, M. Talandier, B. Henri-Nicot \& B. Odzirlik 2008. Les impacts socio-économiques de l'inscription d'un site sur la liste du patrimoine mondial: trois études. Unpublished report prepared for the UNESCO World Heritage Committee. Available from the author of this study.

Rebanks Consulting and Trend Business Research 2009. World Heritage status: is there opportunity for economic gain? Research and analysis of the socio-economic impact potential of UNESCO World Heritage site status. Penrith

Reinius, S.W. \& P. Fredman 2007. Protected areas as attractions. Annals of Tourism Research 34 (4): 839-854.

Roberts, T. \& P.J.S. Jones 2013. North East Kent European marine site: Overcoming barriers to conservation through community engagement. Marine Policy 41 (0): 33-40.

Slocombe, S. \& P. Dearden 2002. Protected areas and ecosystem-based management. In: Dearden, P. \& R. Rollins (eds.), Parks and protected areas in Canada. Planning and management. Don Mills, Ont.: 295-320.

Tisdell, C. 2010. World Heritage listing of Australian natural sites: Effects on tourism, economic value and conservation. Working Papers on Economics, Ecology and the Environment No. 172: 1-45.

Tisdell, C. \& C. Wilson 2001. World Heritage listing of Australian natural sites: tourism stimulus and its economic value. Working Paper No. 60. Queensland.

UNESCO 1972. Convention concerning the protection of the world cultural and natural heritage. Adopted by the general conference at its $17^{\text {th }}$ session in Paris, $16^{\text {th }}$ November 1972. Paris.

UNESCO 1994. Operational guidelines for the implementation of the World Heritage convention. Paris.
UNESCO 2011. Operational guidelines for the implementation of the World Heritage convention. Paris.

UNESCO 2013. World Heritage list. Available at: http://whc.unesco.org/en/list/ (accessed: 15/08/13)

UNESCO 2014. World Heritage and Sustainable Tourism Programme. Available at: http:/ / whc.unesco. org/en/tourism/ (accessed: 10/12/13)

UNESCO, ICCROM, ICOMOS \& IUCN 2012. Managing Natural World Heritage. World Heritage Resource Manual. Paris.

Urquhart, C. 2013. Grounded theory for qualitative research. A practical guide. London.

Wallner, A. \& U. Wiesmann. 2009. Critical issues in managing protected areas by multi-stakeholder participation - analysis of a process in the Swiss Alps. eco. mont 1 (1): 45-50.

Weichhart, P. 1992. Heimatbindung und Weltverantwortung. Widersprüchliche oder komplementäre Motivkonstellationen menschlichen Handlens? Geographie beute 100 (13): 30-44.

WHC 2002. Decisions adopted by the World Heritage Committee at its $26^{\text {th }}$ session in Budapest. 26.COM/9. Paris.

WHC 2009. Reflection on the future of the World Heritage Convention. $33^{\text {rd }}$ Session of the World Heritage Committee in Seville, Spain. WHC-09/33.COM/14A. Paris.

WHC 2010a. Decision adopted by the World Heritage Committee at its $34^{\text {th }}$ Session in Brasilia, Brazil. WHC10/34. COM/20. Paris.

WHC 2010b. World Heritage Convention and sustainable development. $34^{\text {th }}$ Session of the World Heritage Committee in Brasilia, Brazil. WHC-10/34.COM/5D. Paris.

WHC 2012. Decisions adopted by the World Heritage Committee at its $36^{\text {th }}$ Session in St. Petersburg, Russia. WHC-12/36.COM/19. Paris.

\section{Authors}

\section{Katharina Conradin}

Centre for Development and Environment, University of Bern, Hallerstrasse 10, 3012 Bern, Switzerland.Email: k.conradin@gmail.com

\section{Urs Wiesmann}

Department of Integrative Geography, University of Bern, Hallerstrasse 12, 3012 Bern, Switzerland. Email: urs.wiesmann@cde.unibe.ch 